\title{
The Compatibility of Spindor Dust with Poecilia reticulata for Integrated Mosquito Larviciding
}

\author{
Anogwih JA ${ }^{1 *}$, Saliu JK ${ }^{1}$, Linton EW², Makanjuola WA ${ }^{1}$ and Chukwu $\mathrm{LO}^{3}$
}

${ }^{1}$ Department of Zoology, University of Lagos, Nigeria

${ }^{2}$ Biology Department, Central Michigan University, Nigeria

${ }^{3}$ Department of Marine Sciences, University of Lagos, Nigeria

\begin{abstract}
Background: The compatibility of spindor dust (spinosad), a bio-rational larvicide derived from the fermentation of a soil bacterium Saccharopolyspora spinosa, was investigated on the mosquito fish, Poecilia reticulata, and larvae of both Anopheles gambiae s.s. and Culex quinquefasciatus mosquitoes.
\end{abstract}

Methods: Three replicates of each to different concentrations of spinosad dust under static bioassay were performed to determine the acute toxicity of the larvicide on each organism. To investigate the genotoxic and ultrastructural changes in $P$. reticulata, the fish were exposed for 28 days to low concentrations of the test larvicide capable of killing $30 \%$ and $70 \%$ of $C x$. quinquefasciatus larvae. Thereafter, gill and intestinal cells were removed at days 3 and 28 respectively, and then processed for epifluorescent and transmission electron microscopic studies.

Results: Spinosad showed no lethal toxic effect on $P$. reticulata but caused an appreciable mortality to Anopheles and Culex larvae with $24 \mathrm{~h} \mathrm{LC}_{50}$ values of $59.34 \mathrm{\mu gL}^{-1}$ and $73.06 \mathrm{\mu gL}^{-1}$ respectively. The larvicide failed to significantly induce micronuclei in the fish as determined with acridine orange assay $(P>0.05)$. Marked damage characterised by pycnotic nuclei, loss of cristae in mitochondria, dense and degraded cytoplasm was mostly found in the exposed intestinal cells of the fish and the damage severity increased with increasing concentration of spinosad.

Conclusion: Spinosad at $49 \mathrm{\mu gL}^{-1}$ seems to be the threshold above which severe damage occurred in the fish. Therefore, spinosad is only compatible with $P$. reticulata for integrated mosquito larval control at concentration not greater than $49 \mu \mathrm{gL}^{-1}$.

Keywords: Spinosad; Larvicide; Poecilia reticulate; Anopheles gambiae s.s; Culex quinquefasciatus

\section{Introduction}

Current efforts at mosquito control in Nigeria and indeed the whole of Africa have gradually drifted away from the more traditional larviciding and environmental management to almost solely on disease management and domestic adulticiding since the discovery of the dangers of Dichlorodiphenyltrichloroethane (DDT). Despite ease of application, disease management and adulticiding alone have failed to interrupt mosquito vector burden on a nationwide basis evidenced by the continual establishment of new cases of mosquito related diseases and subsequently death, particularly amongst children under the age of five and pregnant women [1]. While it is true that mosquitoes cannot be totally eliminated in any ecosystem, good mosquito management practices that consider environmental issues must be adopted within the purview of Integrated Vector Management (IVM) to keep mosquito population below the level of public health concern. Integrated Vector Management is the targeted use of different vector control methods alone or in combination to achieve the greatest disease control benefits in the most cost effective manner while minimising negative impacts on the ecosystem e.g. depletion of biodiversity and adverse side effects on public health [2].

The larval stages of mosquito vector are the most vulnerable stages because they are confined by their nature to various aquatic media making control practices easier, more effective and highly sustainable. When mosquito larvae are effectively targeted, the transmission chain in the mosquito life cycle is broken, thereby resulting in a more sustainable mosquito control programme. Therefore, to achieve an effective and long lasting mosquito control programme there is a need to reprioritize larval control practice and adopt the "double barreled" approach inherent in a good IVM System. Existing and efficacious chemical larval control methods can be combined with non-chemical larval control methods such as the use of guppy fish that occupy several open drainages in Lagos, Nigeria. Guppies have been credited for their high larvivorus potential against mosquito vectors in many parts of the world [3-10]. As efficient biological control agent, guppies need to be protected from the deleterious effects of larvicides. Spinosad is an insect control product derived from the fermentation of a soil bacterium Saccharopolyspora spinosa [11]. This compound was shown to cause cytogenotoxic damage to guppy species at higher concentration [12].

It was therefore pertinent to conduct an initial investigation on the genotoxic and ultra structural effects of the biolarvicide at low concentrations in bid to establish a dosage solution that is compatible to apply in an aquatic ecosystem particularly for integrated mosquito larval control practice where the integrity of the fish as a support control agent is to be ensured. Micronucleus (MN) is considered as the most suitable and effective method to use in fish when evaluating the genotoxic effects of xenobiotics because of its simplicity and ease of scoring [13-15]. The success of integrated mosquito larval control

*Corresponding author: Anogwih JA, Department of Zoology, University of Lagos, Nigeria, Tel: +2348035506661; E-mail : janogwih@unilag.edu.ng

Received July 14, 2013; Accepted September 27, 2013; Published October 07 2013

Citation: Anogwih JA, Saliu JK, Linton EW, Makanjuola WA, Chukwu LO (2013) The Compatibility of Spindor Dust with Poecilia reticulata for Integrated Mosquito Larviciding. J Clin Res Bioeth 4: 157. doi:10.4172/2155-9627.1000157

Copyright: (c) 2013 Anogwih JA, et al. This is an open-access article distributed under the terms of the Creative Commons Attribution License, which permits unrestricted use, distribution, and reproduction in any medium, provided the original author and source are credited. 
will rely greatly on the data generated from this study hence the aim of this research was to determine a concentration of spinosad that will effectively reduce mosquito vector population with minimal deleterious impact on the non-target biological control component of an IVM programme.

\section{Materials and Methods}

\section{Collection of test organisms}

Poecilia reticulata were collected in the morning hours from drainage at Christian Missionary Grammar School (CMS), Yaba, Nigeria (N6.533048, 3.388424E), and using fish net of mesh size 1.5 $\mathrm{mm}$ in diameter. Similarly, a five-litre capacity container was used to take five scoops of Culex larvae from an opposite drainage to the guppy's collection site (N6.534327, 3.390012E). Fish and Culex larvae were transported to the Zoology Department, University of Lagos, Nigeria in different buckets. Anopheles larvae were collected from the University Biological Garden (N6.51841, 3.400679E) by setting up ten oviposition traps made out of plastic containers. The containers were placed randomly within the garden at $1.5 \mathrm{~m}$ height. They were half filled with dechlorinated tap water with few dried leaves placed at the bottom of each container to give a dull background, attractive to gravid Anopheles females. An oviposition substrate (Whatman No 1 filter paper) was then lined vertically inside the containers where gravid females preferred to lay eggs just above the water level. Traps were monitored daily for the presence of mosquito larvae that were then collected and taken to the laboratory in transparent plastics containing dechlorinated tap water. Approximately 1,100 Anopheles and 2,300 Culex larvae were collected.

\section{Breeding/Rearing of test organisms}

The fishes were released into a $200 \mathrm{~L}$ holding tank containing dechlorinated tap water at $\mathrm{pH}$ 7. They were reared under laboratory condition of $28^{\circ} \mathrm{C} \pm 0.8,72 \% \pm 2 \%$ relative humidity and a $12: 12 \mathrm{~h}$ light: dark regime. The tank was drained then washed and refilled with fresh dechlorinated tap water twice weekly to prevent the accumulation of fish metabolic wastes. After 8 days of acclimatization period, selected brood stocks were transferred into 5 litres plastic containers to obtain offspring. After 3-4 weeks, a cycle of reproduction was completed, and 2 day old juveniles were separated from adults and introduced into 2 litres of well aerated dechlorinated tap water where they were allowed to mature into adults, mean length $3.5 \pm 0.2 \mathrm{~cm}$. Mosquito species were separated into their respective types using the keys of Oyerinde [16]. Larvae from Anopheline and Culicine mosquitoes were then separately collected with nylon mesh and each poured into five $500 \mathrm{ml}$ transparent plastic containers, half filled with dechlorinated tap water in which a mixture of $1.50 \mathrm{~g}$ mice pellets and $0.7 \mathrm{~g}$ yeast were added on a daily basis.

Approximately 50 larvae were introduced into each plastic container to avoid overcrowding. The media were changed every $48 \mathrm{~h}$ to avoid fungal growth from the feed and metabolic wastes. Larvae were then left to metamorphose into pupal stage. With the aid of a nylon mesh, pupae from each type were separately placed into $500 \mathrm{ml}$ glass beaker half filled with dechlorinated tap water. Three beakers, with approximately 70 pupae from each type were placed into mosquito cages to trap their respective emerging adults. Adults were initially fed on a $10 \%$ glucose solution soaked into cotton wool. Five adult mosquitoes from each type were removed, frozen in plastic cups and taken to the Entomological Unit of the Nigeria Institute of Medical Research (NIMR) for proper identification. The breeding process continued in the laboratory up to five generational levels for bioassay. Mosquito species were identified as Culex quinquefasciatus and Anopheles gambiae s.s.

\section{Acute toxicity test}

Spinosad with active ingredient $1.25 \mathrm{~g} / \mathrm{kg}$ consisting of Spinosyns A (CAS: 131929-60-7) and D (CAS: 131929-63-0) was obtained as spindor dust from Nigeria Stored Product Research Institute, Yaba (NSPRI). A stock solution of the larvicide was prepared to a final concentration of $1.25 \mathrm{mgL}^{-1}$ using dechlorinated tap water as diluent. Thereafter, serial dilutions were prepared for acute toxicity test against mosquito larvae as follows: $0 \mu \mathrm{gL}^{-1}, 25 \mu \mathrm{gL}^{-1}, 50 \mu \mathrm{gL}^{-1}, 75 \mu \mathrm{gL}^{-1}, 100 \mu \mathrm{gL}^{-1}, 125 \mu \mathrm{gL}^{-1}, 150$ $\mu \mathrm{gL}^{-1}$ and guppies: $0 \mu \mathrm{gL}^{-1}, 20 \mu \mathrm{gL}^{-1}, 40 \mu \mathrm{gL}^{-1}, 100 \mu \mathrm{gL}^{-1}, 250 \mu \mathrm{gL}^{-1}, 500$ $\mu \mathrm{gL}^{-1}, 1500 \mu \mathrm{gL}^{-1}$. Prior to the start of experiment, the physicochemical characteristics $(\mathrm{pH}$, dissolved oxygen, conductivity and temperature) of the test media and dechlorinated tap water (control) were analyzed with a pH meter $\left({ }^{\odot}\right.$ Mettler Toledo AG), DO meter $\left({ }^{\circledR}\right.$ Mettler Toledo AG), Conductivity meter $\left({ }^{\odot}\right.$ Mettler Toledo AG) and Stem Glass Thermometer (Uniscope) respectively. Poecilia reticulata were not fed $24 \mathrm{~h}$ prior to bioassay. Three replicates of 25 fish of mean size $3.5 \pm 0.2 \mathrm{~cm}$ were randomly selected and placed in different bioassay containers of capacity 1litre, each half filled with control and treated media at earlier stated concentrations. Similarly, active $4^{\text {th }}$ instar mosquito larvae of Anopheles and Culex species in three replicates of 50 each were randomly selected and respectively placed in bioassay containers of capacity 1litre, each half filled with treated and untreated media at earlier stated concentrations. A fish or larva was classified as dead if it failed to move when gently probed with the edge of a glass rod. Mortality was less than $5 \%$ in each container holding control fish and larvae.

\section{Selection of test concentrations for sub-lethal toxicity studies}

Low concentrations of spinosad, $49 \mu \mathrm{gL}^{-1}$ and $110 \mu \mathrm{gL}^{-1}$ that were within the range that killed $30 \%$ and $70 \%$ of $C x$. quinquefasciatus larvae respectively but did not cause mortality in guppy or impair the fish feeding potential during acute toxicity study were selected for Acridine Orange (AO) and Transmission Electron Microscopy (TEM) analyses. The Culex sp. was selected for study because it was more tolerant to spinosad than Anopheles sp., based on the result from acute toxicity test. For the Acridine assay, benzene (CAS: 71-43-2) which is a known mutagen was selected as the positive control at $0.8 \mu \mathrm{gL}^{-1}[17,18]$.

\section{Acridine orange assay}

Fish were not fed $24 \mathrm{~h}$ before testing and a 28-day static-renewal bioassay was utilized where the test media were renewed at the same concentration once every $48 \mathrm{~h}$ [19]. Fish of mean length $3.5 \pm 0.2 \mathrm{~cm}$ were randomly selected and divided into 3 groups (21fish/group). At day 3 and 14 respectively, three fish were randomly selected from each replicate of treatment, negative and positive control groups respectively and immediately dissected to remove gill arches. Gill cells were processed for structural analysis using the induction of micronucleus as adapted by Cavas [15]. Gill cells were smeared on clean slides and fixed in three successive changes of methanol-acetic acid solution of ratio 1:3 v/v. After $24 \mathrm{~h}$, phosphate buffer solution ( $\mathrm{pH}$ 7.4) containing $\mathrm{AO}$ at a concentration of $0.003 \%$ was dropped on each slide, then covered with cover slips, sealed with transparent nail polish. Three slides were prepared from each randomly selected fish in each replicate with controls. Prepared slides were viewed for the presence of micronuclei with $63 \mathrm{x} / 1.4$ oil immersion under Olympus BX51 microscope. One thousand five hundred (1500) cells were scored from each slide. Micronuclei were detected as exhibiting yellow 
Citation: Anogwih JA, Saliu JK, Linton EW, Makanjuola WA, Chukwu LO (2013) The Compatibility of Spindor Dust with Poecilia reticulata for Integrated Mosquito Larviciding. J Clin Res Bioeth 4: 157. doi:10.4172/2155-9627.1000157

Page 3 of 6

green fluorescence under blue excitation using an FITC barrier filter. Micronuclei were described according to Al-Sabti and Metcalfe [14] and Cavas [15]

\section{Transmission electron microscopy}

At day 28, three fish were randomly selected from each concentration in the treatment group along with control fish for dissection to remove intestinal tissue. Tissue was immediately fixed with $1.25 \%$ glutaraldehyde (EMS, USA) in $0.10 \mathrm{M}$ phosphate buffer solution, $\mathrm{pH} 7.4$ at $4^{\circ} \mathrm{C}$ for $1 \mathrm{~h}$ in the dark, and then rinsed three times in phosphate buffer solution $\mathrm{pH}$ 7.4. Each rinse lasted for 15 minutes in the cold and dark. Tissue was post-fixed in un buffered $2 \%$ osmium tetroxide for $2 \mathrm{~h}$ at room temperature in the hood, and then rinsed two times in distilled water for 5 minutes, each. This was followed by an ascending series of graded alcohol dehydrations (25\%, 50\%, $75 \%$, $95 \%$ and $100 \%)$. After $24 \mathrm{~h}$, tissue was in filtered with Spurr's resin, 2:1 then 1:2 (ethanol: plastic) on a rotator, followed by two $100 \%$ plastic changes on a rotator. Each series of infiltration lasted for over $8 \mathrm{~h}$. Tissue samples were then embedded using a siliconized rubber mould with Spurr and placed in $60^{\circ} \mathrm{C}$ oven overnight. Samples were removed after $24 \mathrm{~h}$ and allowed to cool. Hardness was checked followed by trimming of the blocks for sectioning. Thick sections $(1 \mu \mathrm{m})$ were cut with glass knife and stained with toluidine blue dye. The sections were then examined by light microscopy to select areas for fine structural study and photomicrography. Ultrathin sections $(80 \mathrm{~nm})$ were cut with an MT-2B ultramicrotome (Sorvall) using a glass knife. The ultrathin sections were taken on 300 mesh copper grid and stained with 2\% Uranyl Acetate and Reynold's lead citrate solution for 30 and 3 minutes, respectively. The samples were imaged at $80 \mathrm{kV}$ with Philips CM-10 Transmission Electron Microscope.

\section{Statistical analysis}

The dose mortality response of the $24 \mathrm{~h}$ toxicity test was analyzed with Probits while the Student paired sample T-test was used to analyze the significant differences in the frequency of micronucleus in treated and control media. Both statistical tools were obtained from SPSS Version 15.0 for Windows (SPSS Inc. Chicago, IL, USA).

\section{Results}

\section{Physicochemistry of the medium}

All treatments were maintained under the same conditions, resulting in nearly identical physicochemical values for the control and spinosad treated media (Table 1). Thus, indicating that spinosad was the only difference among the treatments.

\section{Acute toxicity and susceptibility of test organisms}

An. gambiae s.s. was the more susceptible target organism with a susceptibility factor (SF) of 1.00 and $\mathrm{LC}_{50}$ value estimated at $59.34 \mu \mathrm{gL}^{-1}$ (13.43-104.39), compared to $C x$. quinquefasciatus $\mathrm{SF}=1.2$ and $\mathrm{LC}_{50}$ value at $73.08 \mu \mathrm{gL}^{-1}$ (55.29 - 93.01) (Figure 1). Spinosad compound exerted no lethal toxicity on $P$. reticulata within the tested concentrations; therefore a mean lethal concentration could not be determined.

\section{Frequency of micronuclei with AO assay}

At both days 3 and 14, observations of micronuclei were not significantly $(\mathrm{P}>0.05)$ induced in spinosad treated gill cells except with the benzene group (Table 2). The patterns of induction of micronuclei are shown in Figures 2 and 3.

\section{TEM of Intestinal cells of guppy}

Figures 4-9 show the results of the TEM examination of intestinal cells of control and exposed fish. In the control group, the cytoplasm and nuclear membrane were with well-defined nucleus and one nucleolus just as in the mitochondria with distinct cristae and well defined matrices (Figures 4 and 7). In the treated cells however, there were cell distortions that became more severe with increasing concentration of the larvicide. Minimal damage occurred only in the nucleus at lower concentration of $49 \mathrm{\mu gL}^{-1}$ including nucleus elongation with rearranged chromatin, presence of large secretory vesicles and electron dense cytoplasm (Figures 5 and 8). At higher concentration of $110 \mu \mathrm{gL}^{-1}$ severe damage characterized by electron dense and degraded cytoplasm with

\begin{tabular}{|c|c|c|}
\hline Parameters & Control & Spinosad \\
\hline $\mathrm{pH}$ & 6.80 & $6.75-6.77$ \\
Conductivity & $0.09 \mathrm{mgL}^{-1}$ & $0.09 \mathrm{mgL}^{-1}-0.091 \mathrm{mgL}^{-1}$ \\
Dissolved Oxygen (DO) & $4.90 \mathrm{mgL}^{-1}$ & $5.00 \mathrm{mgL}^{-1}-5.01 \mathrm{mgL}^{-1}$ \\
Temperature & $23.0^{\circ} \mathrm{C}$ & $23.10^{\circ} \mathrm{C}-23.11^{\circ} \mathrm{C}$ \\
\hline
\end{tabular}

Table 1: Mean physic-chemical values of the medium.
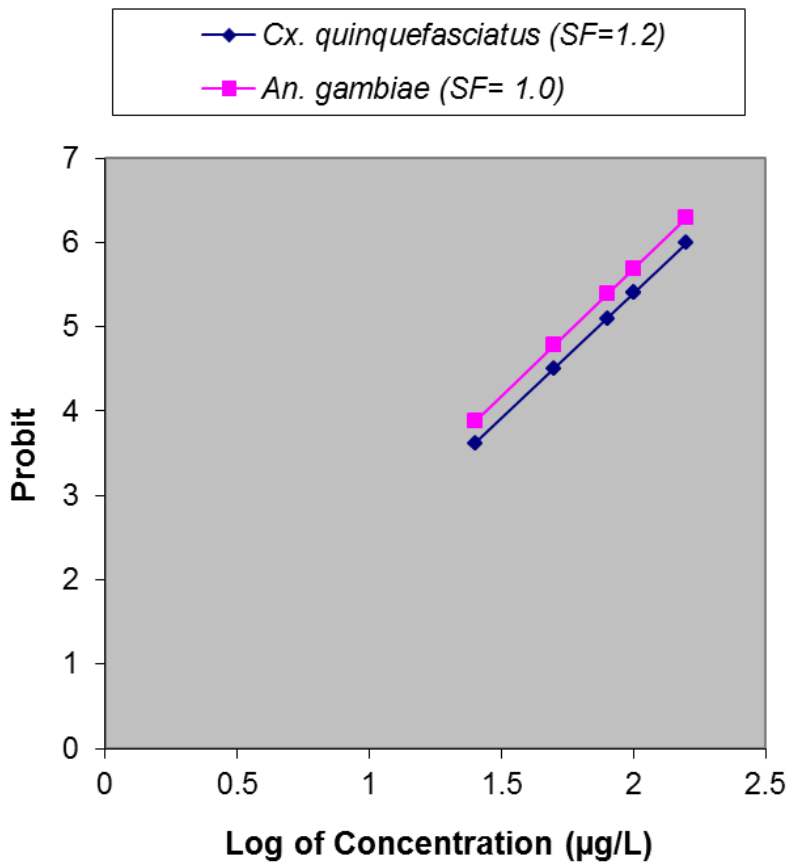

Figure 1: Acridine orange stained gill cells of $P$. reticulata observed with BX51 fluoview microscope at $63 \mathrm{x} / 1.4$ oil immersions.

\begin{tabular}{|c|c|c|c|}
\hline Day & Treatment & Concentration $\left(\boldsymbol{\mu g L ^ { - 1 } )}\right.$ & Frequency (Mean \pm SE) \\
\hline 3 & Negative control & 0 & $0.33 \pm 0.33$ \\
& Positive control & 0.8 & $5.00 \pm 1.00^{\circ}$ \\
& Spinosad & 49 & $0.00 \pm 0.00^{\text {ns }}$ \\
\multirow{4}{*}{14} & & 110 & $1.67 \pm 0.88^{\text {ns }}$ \\
& Negative control & 0 & $0.00 \pm 0.00$ \\
& Positive control & 0.8 & $5.33 \pm 1.86^{\circ}$ \\
& Spinosad & 49 & $0.00 \pm 0.00^{\text {ns }}$ \\
& & 110 & $0.33 \pm 0.33^{\text {ns }}$ \\
\hline
\end{tabular}

${ }^{\circ} \mathrm{P}<0.05$

ns $=$ not significant at $\mathrm{P}=0.05$

Table 2: Frequency of Micronuclei in Poecilia reticulata at low concentration. 
Citation: Anogwih JA, Saliu JK, Linton EW, Makanjuola WA, Chukwu LO (2013) The Compatibility of Spindor Dust with Poecilia reticulata for Integrated Mosquito Larviciding. J Clin Res Bioeth 4: 157. doi:10.4172/2155-9627.1000157

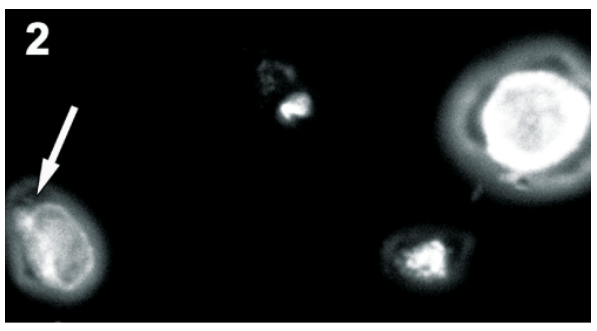

Figure 2: Mature cell (NCE) with micronucleus (arrow).

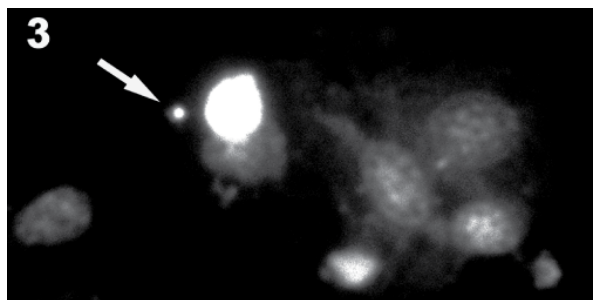

Figure 3: Immature (PCE) cell with micronucleus (arrow)

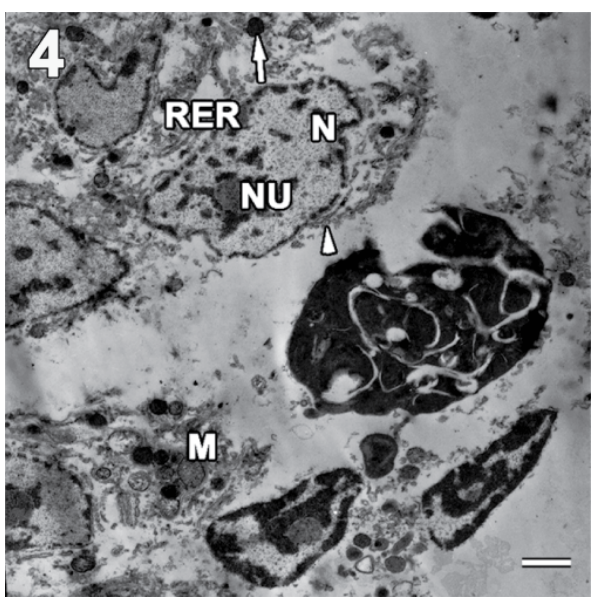

Figures 4: TEM of $P$. reticulata intestinal nuclear cells showing control fish and exposed fish, Intact cytoplasmic and nuclear membrane with welldefined nucleus (N) and one nucleolus (NU). Cell organelles are intact as in Mitochondria (M); Lysosomes (Ly); Rough Endoplasmic Reticulum (RER); Smooth Endoplasmic Reticulum (arrow) scale bar $1 \mu \mathrm{m}$.

inclusions, presence of pycnotic nuclei, ruptured lysosome and fewer cristae in mitochondria was found (Figures 6 and 9).

\section{Discussion}

Spinosad compound exerted no lethal toxicity on $P$. reticulata within the tested concentrations therefore a mean lethal concentration could not be determined implying that the compound can be used to kill mosquito larvae without causing mortality in the fish species making it a good larvicide for integrated mosquito larval control. Pest Management Regulatory Agency [20], reported the toxicity of spinosad to aquatic invertebrates including Daphnia sp, Chironomids, shrimp and molluscs, albeit, in comparison to an organophosphate, spinosad was 5 times less toxic to non-target species during continuous exposure studies [21]. Toxicity to fish by spinosad is classified as low to moderate with $96 \mathrm{~h} \mathrm{LC}_{50}$ values between 5 and 30 p.p.m depending on the species

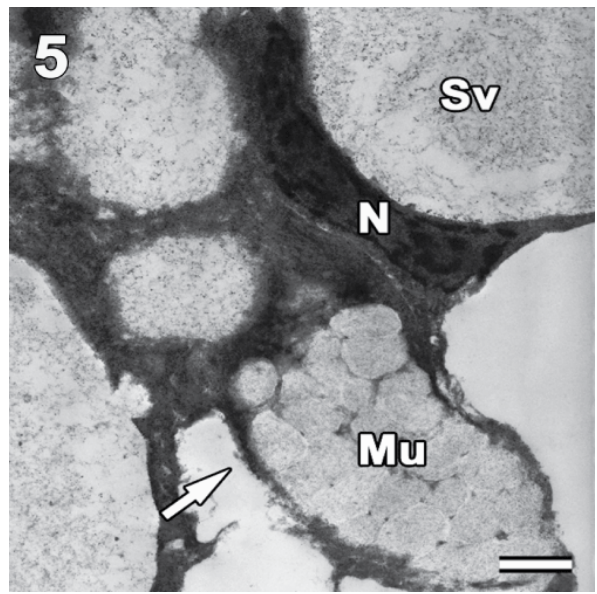

Figure 5: At $49 \mu \mathrm{gL}-1$ features included electron dense cytoplasm and nucleus compared to control, unevenly elongated Nucleus $(\mathrm{N})$ with rearranged chromatin, presence of large Secretory vesicles (Sv), and Mucin (Mu), scale bar $1 \mu \mathrm{m}$.

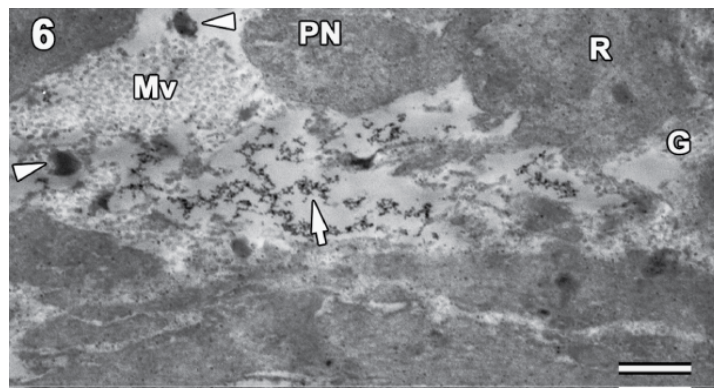

Figure 6: Severe distortion in the cytoplasmic membrane was seen at higher concentration of $110 \mu \mathrm{gL}-1$ characterized by electron dense cytoplasm and swollen Nuclei $(\mathrm{N})$ with indistinct Nucleolus (NU), vacuolation of nucleus (arrow) and disintegration of cytoplasmic inclusions (arrowhead). Golgi body (G), Lysosomes (Ly), microvilli (Mv), lipid droplet (L), scale bar $0.5 \mu \mathrm{m}$.

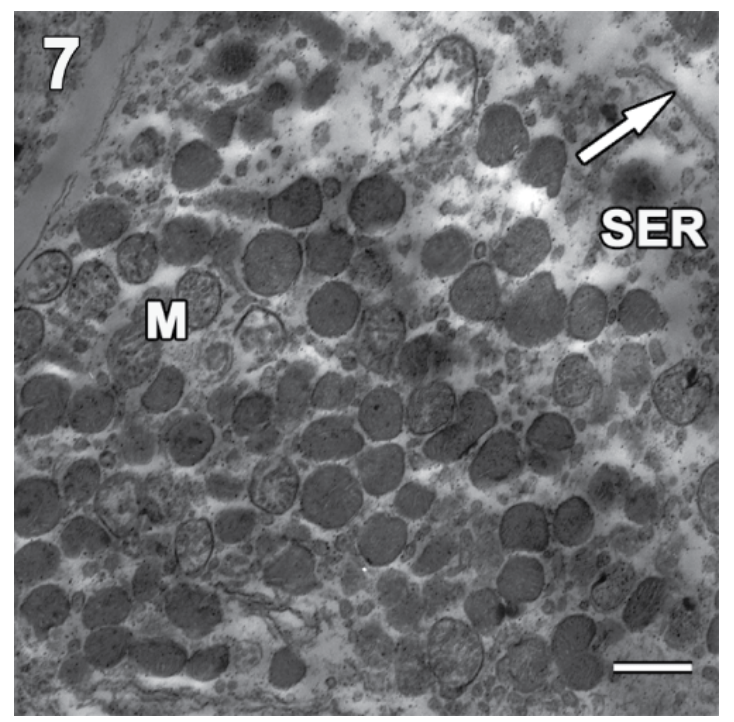

Figures 7: TEM of mitochondrial cells of control fish and exposed fish, control fish showing Mitochondria (M), Smooth Endoplasmic Reticulum (SER); Rough Endoplasmic Reticulum (arrow), scale bar $=0.5 \mu \mathrm{m}$. 
Citation: Anogwih JA, Saliu JK, Linton EW, Makanjuola WA, Chukwu LO (2013) The Compatibility of Spindor Dust with Poecilia reticulata for Integrated Mosquito Larviciding. J Clin Res Bioeth 4: 157. doi:10.4172/2155-9627.1000157

Page 5 of 6

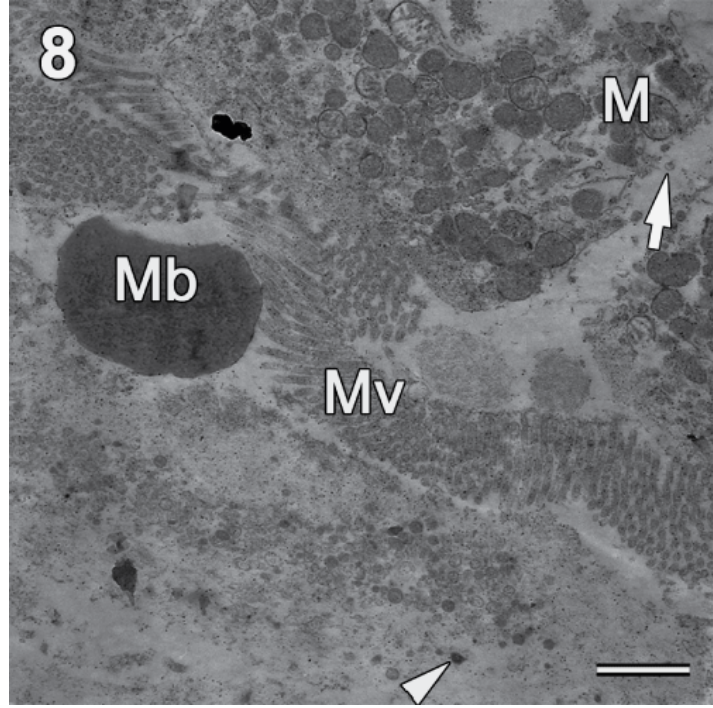

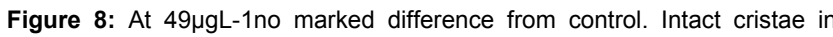
Mitochondria (M), Microbodies (Mb), Microvilli (Mv), Smooth endoplasmic reticulum (arrow), Lysosome (arrow head), scale bar $=1 \mu \mathrm{m}$.

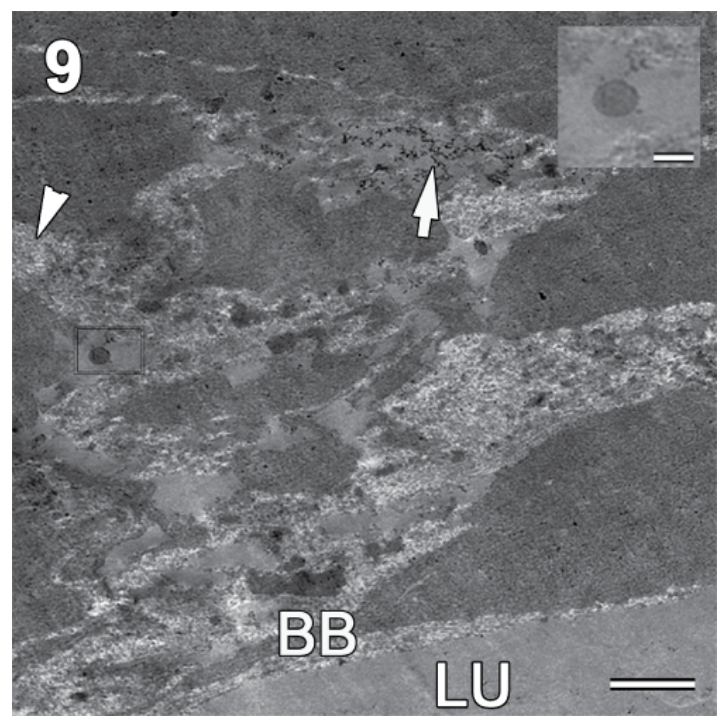

Figure 9: At the highest concentration of $110 \mu \mathrm{L}-1$, there was marked degradation of the electron dense cytoplasm (arrow), mitochondrion with few cristae (inset), Brush border (BB), Lumen (LU), Microvilli (arrow head), scale bars $=1 \mu \mathrm{m}$, Inset $=0.25 \mu \mathrm{m}$.

[11]. Other reports have also shown that spinosad was safe to some non-target organisms [11,22-25] but the impact of spinosad on nontarget aquatic organisms is still poorly understood [26] hence, future research on the compound will necessitate an in-depth sub-chronic and chronic toxicity test on different tissues of various fish species before a final recommendation is made on spinosad use for replacement of organophosphates in field mosquito larval control.

The values of the $50 \%$ mean lethal concentration of $73.06 \mu \mathrm{gL}^{-1}$ and $59.34 \mu \mathrm{gL}^{-1}$ obtained for Cx. quinquefasciatus and An. gambiae s.s. respectively in this study compared favorably with those from other workers. Anthonio et al. [27], estimated a $24 \mathrm{~h} \mathrm{LC}_{50}$ value for spinosad against Aedes aegypti as $0.060 \mathrm{mgAI} / \mathrm{L}$ (range of $95 \%$ confidence limits $0.045-0.079$ ). The $24 \mathrm{~h}$ toxicity of two formulations of spinosad under different water resources against $3^{\text {rd }}$ larval instar of $C x$. pipiens was obtained as $0.002 \mathrm{ppm}$ and $0.007 \mathrm{ppm}$ for liquid and dust formulations respectively and they concluded that the dust formulation had better initial kill on the Culex mosquitoes than the liquid form [28]. Statistically, Cx. quinquefasciatus and An. gambiae s.s. showed the same degree of tolerance to the compound contrary to our expectations considering that immunity may have been conferred on the Culex sp. based on the nature of their natural habitat which is often prone to contamination. However, the higher susceptibility value obtained for $C x$. quinquefasciatus was suggestive of the concentration of larvicide to use for mosquito control practices. The concentration capable of killing the more tolerant larvae species, in this case, culex mosquitoes should be applied to ensure adequate control of other less tolerant species that may co-habit with them.

Spinosad failed to inhibit growth in the fish at reduced concentration evidenced by their inability to significantly induce $\mathrm{MN}$ in the fish gill cells with AO assay however, with TEM analysis, the compound behaved differently. Marked difference from the control was observed at higher concentration of $110 \mu \mathrm{gL}^{-1}$ compared to $49 \mu \mathrm{gL}^{-1}$. The presence of large secretory vesicles and mucus cells that characterized the cells exposed at $49 \mu \mathrm{gL}^{-1}$ was likely to be an initial protective response by the fish to the impacts from the bio-larvicides. Al-Ghanbousi et al. [29], showed the hyper production of mucus in Aphanius dispar following the exposure of the fish species to low concentration of deltamethrin. Another but similar report, demonstrated the increase of secretory vesicles in the gill of $A$. dispar upon exposure to temephos [30]. Researchers have suggested that mucus secretion by gills and intestines play a major role in the protection of these tissues from the environmental impacts of xenobiotics [31-33] however, it is likely that under high concentration or continuous exposures to larvicides, this protective ability in the fish may become compromised hence the need to establish a baseline concentration for effective and sustainable integrated larval control.

Additionally, the elongation of the nucleus under the lowest concentration of spinosad probably suggested that spinosad did not inhibit cell division in the fish which corroborated the result obtained with AO assay. It is true that at both tested concentrations, spinosad failed to inhibit growth in the fish gill with $\mathrm{AO}$ assay but TEM analyses of guppy's intestinal cells revealed otherwise especially the nucleus at higher concentration of $110 \mu \mathrm{gL}^{-1}$. It is also important to note that these concentrations did not result in physical death in the fish, and were within the range already recommended for field mosquito larviciding [34]. The reliance on mortality alone as diagnostic tool for assessing chemical toxicity/safety could be misleading therefore, the need to apply suite of biomarkers on various tissues of an organism for better informed decision. It is also essential to subject spinosad compound to further detailed evaluation.

\section{Conclusion}

In this study, $49 \mu \mathrm{gL}^{-1}$ of spinosad seems to be the threshold above which severe harm occurred in the fish organelles hence, a concentration not greater than $49 \mu \mathrm{gL}^{-1}$ is suggestive for field integrated mosquito larviciding involving the use of fish as a support control agent.

\section{Acknowledgement}

We thank the University of Lagos, Faculty of Science for the student trave grant to the USA for the Microscopy Studies. We appreciate Mr. Phil Oshel of the Microscopy Laboratory, Department of Biology, Central Michigan University, Mount 
Citation: Anogwih JA, Saliu JK, Linton EW, Makanjuola WA, Chukwu LO (2013) The Compatibility of Spindor Dust with Poecilia reticulata for Integrated Mosquito Larviciding. J Clin Res Bioeth 4: 157. doi:10.4172/2155-9627.1000157

Pleasant MI USA 48859, for the training in the use of the Transmission Electron Microscope.

\section{References}

1. FMOH (2005) Plan of Action for Integrated Vector Management for Nigeria.

2. WHO (2008) Malaria Control: the power of integrated action.

3. Meisch MV (1985) Gambusia affinis affinis, Biological control of mosquitoes. American Mosquito Control Association Bulletin.

4. Sabatinelli G, Blanchy S, Majori G, Papakay M (1991) [Impact of the use of larvivorous fish Poecilia reticulata on the transmission of malaria in FIR of Comoros]. Ann Parasitol Hum Comp 66: 84-88.

5. Gupta DK, Bhatt RM, Sharma RC, Gautam AS, Rajnikant (1992) Intradomestic mosquito breeding sources and their management. Indian J Malariol 29: 41-46.

6. Rajnikant, Bhatt RM, Gupta DK, Sharma RC, Srivastava HC, et al. (1993) Observations on mosquito breeding in wells and its control. Indian J Malario 30: $215-220$.

7. Elias M, Islam MS, Kabir MH, Rahman MK (1995) Biological control of mosquito larvae by Guppy fish. Bangladesh Med Res Counc Bull 21: 81-86

8. Chapman, R ., 2000. The impact of larvivorus fish on mosquito larval and pupal densities on known breeding sites in Ahmedabad, India, MSc Thesis, London School of Hygiene and Tropical Medicine.

9. Dua VK, Pandey AC, Swaphil Rai Dash AP (2007) Larvivorus Activity of Poecilia reticulata against Culex quinquefasciatus larvae in a polluted wate drain in Hardwar, India. Journal of American Mosquito Control Association 23 481-483.

10. Anogwih JA, Makanjuola WA (2010) Predator-prey Density of Poecilia retiuclata (guppy) under laboratory investigation. The Zoologist 8: 47-51.

11. Thompson GD, Dutton R, Sparks TC (2000) Spinosad- a case study: an example from a natural product discovery programme. Pest Management Science 56, 696-702

12. Anogwih JA, Makanjuola WA, Chukwu LO (2013) Spinosad induced Cytogentoxic effects on the mosquito fish, Poecilia reticulata. Journal of Clinical Toxicology.

13. Vigfusson NV, Vyse ER, Pernsteiner CA, Dawson RJ (1983) In vivo induction of sister-chromatid exchange in Umbra limi by the insecticides endrin, chlordane, diazinon and guthion. Mutat Res 118: 61-68.

14. al-Sabti K, Metcalfe CD (1995) Fish micronuclei for assessing genotoxicity in water. Mutat Res 343: 121-135.

15. CavaÅ̈ T (2008) In vivo genotoxicity of mercury chloride and lead acetate: Micronucleus test on acridine orange stained fish cells. Food Chem Toxicol 46: $352-358$

16. Oyerinde JP O (1999) Essentials of Tropical Medical Parasitology. Akoka: University of Lagos Press, Nigeria.

17. Cavå̊̈̈ T, Ergene-GÃ IzÃkara S (2003) Evaluation of the genotoxic potential of lambda-cyhalothrin using nuclear and nucleolar biomarkers on fish cells. Mutat Res 534: 93-99.

18. Udroiu I (2006) The micronucleus test in piscine erythrocytes. Aquat Toxico 79: 201-204

19. Wester PW, Canton HH (1992) Histopathological effects in Poecilia reticulata (guppy) exposed to methyl mercury chloride. Toxicol Pathol 20: 81-92.

20. Pest Management Regulatory Agency (2001) Spinosad Success 480SC Natural insect control product. Conserve 480SC Natural insect control product. Regulatory note REG2001-10. Pest Management Regulatory Agency, Health Canada, Ottawa: Canada.
21. Stark JD, Vargas RI (2003) Demographic changes in Daphnia pulex (Leydig) after exposure to the insecticides spinosad and diazinon. Ecotoxicol Environ Saf 56: 334-338.

22. Perez CM, Marina CF, Bond JG, Rojas JC, Valle J, Williams T (2007) Spinosad, a naturally derived insecticide, for control of Aedes aegypti (Diptera: Culicidae) Efficacy, persistence and Elicited Oviposition Response. Journal of Medical Entomology 44: 631-638.

23. Stebbins KE, Bond DM, Novilla MN, Reasor MJ (2002) Spinosad insecticide: subchronic and chronic toxicity and lack of carcinogenicity in CD-1 mice. Toxicol Sci 65: 276-287.

24. Williams T, Valle J, Vinuela E (2003) Is the naturally derived insecticide spinosad compatible with insect Natural Enemies. Biocontrol Science and Technology 13: 459-475.

25. Guidelines for laboratory and field testing of mosquito larvicides World Health Organization communicable disease control, prevention and eradication Geneva, Switzerland: WHO Pesticide Evaluation Scheme, 1-41.

26. Bond JG, Marina CF, Williams T (2004) The naturally derived insecticide spinosad is highly toxic to Aedes and Anopheles mosquito larvae. Med Vet Entomol 18: 50-56.

27. Antonio GE, Sánchez D, Williams T, Marina CF (2009) Paradoxical effects of sublethal exposure to the naturally derived insecticide spinosad in the dengue vector mosquito, Aedes aegypti. Pest Manag Sci 65: 323-326.

28. Baghat MI, El Kady GA, Temarek SA, Lysandrou M (2007) The natural Bioinsecticide spinosad and its toxicity to combat some mosquito species in Ismaila Governorate Egypt. World Journal of Agricultural Sciences 3: 396-400.

29. Al-Ghanbousi R, Ba-Omar T, Victor R (2012) Effect of deltamethrin on the gills of Aphanius dispar: a microscopic study. Tissue Cell 44: 7-14.

30. Ba-Omar TA, Al-Jardani S, Victor R (2011) Effects of pesticide temephos on the gills of Aphanius dispar (Pisces: Cyprinodontidae). Tissue Cell 43: 29-38.

31. FilipoviÄ $\ddagger$ Mariijï $\ddagger$ V, Raspor B (2007) Metallothionein in intestine of red mullet Mullus barbatus as a biomarker of copper exposure in the coastal marine areas. Mar Pollut Bull 54: 935-940.

32. Pawert M, Müller E, Triebskorn R (1998) Ultrastructural changes in fish gills as biomarker to assess small stream pollution. Tissue Cell 30: 617-626.

33. Matey V, Richards JG, Wang Y, Wood CM, Rogers J, et al. (2008) The effect of hypoxia on gill morphology and ionoregulatory status in the Lake Qinghai scaleless carp, Gymnocypris przewalskii. J Exp Biol 211: 1063-1074.

34. Hertlein MB, Mavrotas C, Jousseaume C, Lysandrou M, Thompson GD, et al. (2010) A review of spinosad as a natural product for larval mosquito control. $J$ Am Mosq Control Assoc 26: 67-87. 